\title{
A colonização do saber epidemiológico: uma leitura decolonial da contemporaneidade da pandemia de COVID-19
}

\author{
The colonization of epidemiological knowledge: a decolonial \\ reading of the contemporaneity of the COVID-19 pandemic
}

Gil Sevalho (https://orcid.org/0000-0002-1370-1856) ${ }^{1}$

${ }^{1}$ Departamento de Epidemiologia e Métodos Quantitativos em Saúde, Escola Nacional de Saúde Pública Sergio Arouca, Fundação Oswaldo Cruz. R. Leopoldo Bulhões 1480 Manguinhos, 21041-210. Rio de Janeiro RJ Brasil. gsev@terra.com.br

\begin{abstract}
This paper makes a critical assessment of epidemiology with the COVID-19 pandemic as a social event. It examines the philosophical reflection in which Agamben defines as contemporary those able to stand back to see the dark side of their own era. In the light of decolonial criticism, the concept of "epidemiological transition," with its theory of transcendence of "social determinants of health" and binarism of epidemiological variables as supports of the biomedical and quantitative structuring of the epidemiology of risk factors is queried. The scientific ambition to dominate nature and the engendering of a linear and evolutionary historical time, beginning in western modernity, contextualizes the epistemicides of popular wisdom and the coloniality of epidemiological knowledge. The theoretical constitution of decolonial thought is historically analyzed, highlighting its greater critical potential to reveal the structural colonization of epidemiological knowledge. The post-pandemic future is considered and Prigogine's idea of bifurcation - as elaborated by Sousa Santos - and Paulo Freire's untested feasibility are related with the concept of time as the creation and expectation of social transformation.

Key words Epistemology, Contemporaneity of the COVID-19 pandemic, Epidemiological transition, Social determination of health and binarisms, Decolonial criticism
\end{abstract}

Resumo $O$ ensaio epistemológico relaciona criticamente a epidemiologia com a pandemia de COVID-19 enquanto evento social. Explora-se a reflexão filosófica em que Agamben define contemporâneo como quem é capaz de se afastar e enxergar o lado escuro do seu tempo. À luz da crítica decolonial, questionam-se a ideia de "transição epidemiológica", com sua transcendência na teoria dos "determinantes sociais de saúde", $e$ a disposição binarista das varáveis epidemiológicas, como suportes da estruturação quantitativa e biomédica da epidemiologia dos fatores de risco. A pretensão científica de domínio da natureza e o engendramento de um tempo histórico linear e evolutivo, que inicia com a modernidade ocidental, contextualizam os epistemicídios dos saberes populares e a colonização do saber epidemiológico. Historiciza-se a constituição do pensamento crítico decolonial e pontua-se seu potencial para a revelação do caráter estrutural da colonização do saber epidemiológico. Considera-se o futuro pós-pandemia e relacionam-se as ideias de bifurcação, originada de Ilya Prigogine e elaborada por Boaventura de Sousa Santos, e inédito viável, de Paulo Freire com a concepção do tempo como criação e a expectativa de transformação social.

Palavras-chave Epistemologia, Contemporaneidade da pandemia de COVID-19, Transição epidemiológica, Determinação social da saúde e binarismos, Crítica decolonial 


\section{Introdução}

Para Santos ${ }^{1}$, a história humana é de apropriação e modificação do entorno. À transformação do espaço pela essencial atividade do trabalho somase, porém, a devastação progressiva da natureza em função do acúmulo desmedido de capital.

Epidemias causadas por diferentes tipos de vírus influenza sucedem-se desde meados do século XX: a gripe asiática da década de 1950, a gripe de Hong Kong dos anos 1960, a gripe suina da primeira década do século XXI. Em comum têm procedência asiática e relação com subtipos do vírus influenza HN. A investigação de Hultin, Tautenberger e Reid, nos anos 1990, associou a gripe espanhola de 1918 ao vírus influenza $\mathrm{HN}$, após exame de corpos conservados pelo frio, enterrados no cemitério da aldeia esquimó de Brevig Mission, no Alaska².

A ocorrência de pandemias procedentes da Ásia com transmissão respiratória é ameaça conhecida. Ujvari ${ }^{3}$ aponta que ao aglomerar animais com finalidade econômica os humanos favorecem o surgimento de epidemias (p. 165). O autor sugere a importância do Sudeste Asiático nesta perspectiva e inclui no contexto a epidemia de sars de 2003, uma pneumonia causada por um coronavírus.

A China estruturou-se como economia de mercado expoente no capitalismo globalizado, apresentando a concomitância do novo e do antigo, a intensificação da industrialização e comércio coexistindo com formas tradicionais de viver e se relacionar com a natureza ${ }^{4}$. Características históricas das práticas agrícolas, comércio e alimentação conformam na China e Sudeste Asiático, região que congrega cerca de um quarto da população mundial, condições peculiares para desenvolvimento e circulação de microorganismos entre diferentes espécies, impactando na saúde do mundo.

O mundo atual é da velocidade crescente das trocas e deslocamentos e favorecimento da circulação de microorganismos, com o ser humano e sua biota portátil transportados por meios rápidos e eficazes ${ }^{5}$ (p. 230). A produção capitalista e o consumismo impõem a contínua substituição dos bens, e a mobilidade, física ou imaginária, é condição para geração do lucro financeiro. Segundo Sevalho ${ }^{5}$, quando o tempo é dinheiro a duração é um obstáculo a se vencer e o espaço e o tempo foram colonizados para tal (p. 223).

Debates sobre a presunção do ser humano de fazer da ciência hegemônica a razão capaz de entendimento do mundo e do universo, separan- do-se e assenhorando-se da natureza, fortaleceram-se com o aparecimento das ciências sociais. A busca de identidade própria, com vigor a partir de meados do século XX, liga ciências sociais e epistemologias críticas que vinculam a ciência com o poder econômico e político.

Prigogine e Stengers ${ }^{6}$ afirmam que a ciência criou a imagem de um ser humano só, perante uma natureza passiva e estúpida. Desde as epistemologias da complexidade de Prigogine e Stengers $^{6}$, Morin $^{7}$ e Santos ${ }^{8}$ discute-se a capacidade da ciência dominante para compreender as relações com o meio, problematiza-se a separação entre ser humano e natureza e propõe-se a consideração interdisciplinar de sociedade e natureza como conjuntos de sistemas abertos, não-lineares, trocando matéria, energia e informação com o exterior. Com as Epistemologias do Sul de San$\operatorname{tos}^{9} \mathrm{e}$ a teorização decolonial ${ }^{10-12}$ a crítica epistemológica torna-se debate ético e político sobre a produção e realização da ciência, a hierarquização e a dominação eurocêntrica do conhecimento, a colonização do saber, a consideração do saber popular, o racismo.

Este ensaio pretende tensionar o conhecimento epidemiológico a partir de uma leitura decolonial da ocorrência da pandemia de COVID-19, tendo como referência sua expressão social complexa. O ensaio é forma de texto de procedência literária que permite livres e críticas exploração de conceitos e formulação de questionamentos ${ }^{13}$.

A consideração da pandemia como evento social foi inspirada no trabalho precursor de Stark ${ }^{14}$, de 1977, um ensaio que, pela relevância e atualidade, é revisitado. A epidemia de $\mathrm{CO}$ VID-19, em sua essência social, dá sentido ao texto como chamada para discussão. A originalidade da reflexão crítica está na sua realização desde o ponto de vista decolonial, sendo necessário para a distinção desta especificidade o resgate de críticas anteriores.

Questionamentos sobre o entrelaçamento com a biomedicina ocidental e a fundamentação quantitativa da epidemiologia não são novidade, sendo tema de ensaios teóricos importantes que modelaram a Saúde Coletiva brasileira ${ }^{15-17}$, e no que diz respeito à teoria da transição epidemiológica citem-se as reflexões de Barreto et al..$^{18} \mathrm{e}$ de Menéndez ${ }^{19}$, trabalhos da década de 1990.

Entendemos que tais abordagens não esgotam a questão, que deve ser explorada sob pontos de vista críticos que recentemente se abrem ao debate. O acontecimento da pandemia de COVID-19 intensificou e deu nova conformação a 
apontamentos epistemológicos existentes e fez surgir novos. A crítica decolonial aparece, então, como recurso profícuo na análise da vocação científica da epidemiologia, e diga-se que abordagens decoloniais não costumam frequentar a literatura da área e tampouco se apresentaram como fontes do saber formador da Saúde Coletiva brasileira.

A argumentação epistemológica parte de um certo sentido filosófico de contemporaneidade e se debruça sobre elementos do discurso epidemiológico, com ênfase na ideia de transição epidemiológica. A epidemiologia procura se aproximar dos pressupostos de dureza e rigor das ciências naturais, e a teoria da transição epidemiológica, com sua lógica transcendência na determinação social da saúde, sustenta tal projeto e serve como dispositivo para a colonização do saber epidemiológico.

\section{A contemporaneidade da epidemia}

Em junho de 2021, a epidemia de COVID-19 ultrapassava 170 milhões de casos e 3,7 milhões de mortes ${ }^{20}$. Todas as regiões do mundo são afetadas, novas variantes mutantes do vírus com características epidemiológicas distintas são encontradas e novos comprometimentos clínicos descobertos.

Contar do tempo que ainda vivemos é difícil. Imersos no acontecimento não conseguimos distinguir limites, contornos, profundidades, tanto mais quando o acontecimento é dramático.

Nora $^{21}$ considera a dificuldade de se fazer uma história da atualidade. Promover o vivido em histórico faz com que a natureza do contexto se transforme (p. 53). A história do presente é cruel, pois quando se trabalha com carne viva, ela reage e sangra (p. 53). É uma história que fere porque fatalmente se coloca contra a imagem que uma sociedade tem necessidade de construir acerca de si mesma para sobreviver (p. 53).

Certamente inscreve-se no contexto o sentido da afirmação de Braude ${ }^{22}$ de que a maneira singular do historiador se interessar pelo presente é dele se desligar (p. 124).

Para Agamben ${ }^{23}$, contemporâneo é aquele que consegue sair do seu tempo e enxergar o que não seria possível quando atado ao presente. A discronia, no entanto, não significa que o contemporâneo desconheça que pertence irrevogavelmente ao seu tempo, com o qual tem relação de aderência e distância (p. 59).

O contemporâneo, segundo Agamben ${ }^{23}$, fratura as vértebras de seu tempo, e faz da quebra $o$ lugar de um compromisso e de um encontro entre os tempos e as gerações (p. 71). Contemporâneo é quem fixa o olhar no seu tempo para perceber não as luzes, mas o escuro, é quem sabe ver a obscuridade e é capaz de escrever mergulhando a pena nas trevas do presente (p. 62-63).

Pode dizer-se contemporâneo apenas quem não se deixa cegar pelas luzes do século e consegue entrever nessas a parte da sombra, a sua intima obscuridade $^{23}$ (p. 63-64). Contemporâneo, diz Agamben $^{23}$, é aquele que recebe em pleno rosto o facho de trevas que provém do seu tempo (p. 64).

É nesta perspectiva de contemporaneidade que inscrevemos a pandemia de COVID-19 como chamada para desenvolver a crítica do saber epidemiológico.

\section{Epidemiologia dos fatores de risco e determinação social da saúde}

Para Thomas Kuhn ${ }^{24}$, a força dos paradigmas científicos permite que convertam o que é $a n \hat{o}-$ malo em esperado, e, assim, permaneçam vigentes (p. 78). Isto deve se aplicar ao sentido de como a dimensão social foi incorporada à epidemiologia dos fatores de risco operada pela ideia de estilo de vida, central na teoria dos determinantes sociais de saúde. Determinantes sociais de saúde e transição epidemiológica são construções teóricas que dão elasticidade ao paradigma da epidemiologia dos fatores de risco, compondo a dominação pelo saber biomédico e evitando o desconforto da vinculação da questão social com a ordem político-econômica imperante.

Profissionais da saúde e cientistas, em todo mundo, não medem esforços na atenção aos doentes e na pesquisa de tratamentos e vacinas para a COVID-19. Afirmações que engrandecem uma ciência limitada ao saber biomédico como único instrumento capaz de vencer a pandemia são repetidas insistentemente. Discursos recorrentes, com intuito de alertar sobre os riscos da epidemia, sustentam que a epidemia não distingue socialmente suas vítimas. Evidencia-se, no entanto, a determinação social da epidemia que faz com que os socialmente vulneráveis sofram mais seus efeitos, quer no acesso a serviços e tecnologias, inclusive às vacinas que surgem, quer na contaminação, gravidade e morte, quer em perdas relativas às condições de vida, direitos, trabalho.

A ideia dos determinantes sociais de saúde contextualizada na epidemiologia dos fatores de risco foi modelada por Dahlgren e Whitehead ${ }^{25}$, adotada e promovida pela Organização Mundial de Saúde (OMS). A proposta é ancorada na ca- 
tegoria estilos de vida, que define a natureza da relação entre o biológico e o social, funcionando como conceito operador para mudança entre vida insalubre e vida saudável. A ideia de estilos de vida condiz com o culto da modernidade ocidental ao individualismo.

A promoção da saúde, nascida no Canadá na década de 1970 e internacionalizada pela OMS, filia-se ao modelo preconizando ações educativas orientadas segundo padrões de civilidade e saúde ditados pelas sociedades ocidentais capitalistas desenvolvidas, em acordo com o saber biomédico universalizado. Acompanhando o avanço do neoliberalismo, o afastamento do Estado da função de provedor de políticas e ações sociais voltadas para saúde, educação, trabalho, explica as concepções de Estado mínimo ou ausente que dão sentido à promoção da saúde.

Posicionando-se na defesa crítica de uma dialética da determinação social da saúde, Brei$\mathrm{lh}^{26}$ aponta que o paradigma do risco foi concebido para manejar 'fatores' bem definidos, localizados e de curto prazo de ação (p. 197). Constitui estratégia positivista que esvazia o conteúdo histórico, reifica fatores que fragmentam a visão processual, alimenta o reducionismo probabilístico, o nivelamento ontológico, metodológico e praxiológico e a ambiguidade interpretativa da determinação da saúde ${ }^{26}$ (p. 199).

A teoria do risco, e sua centralização na ideia de estilos de vida, segundo Breilh ${ }^{26}$, é de enorme utilidade para os modelos de gestão neoliberal e para a manipulação da hegemonia na saúde, constituindo a base de uma epidemiologia sem memória e sem sonhos de emancipação presa à ditadura de um presente que se mantém à custa de mudanças cosméticas que deixam intacta a estrutura insalubre (p. 202). Não somos expostos aos riscos, assinala Breilh, mas estes nos são impostos pela ordem social. A epidemiologia ocidental hegemônica desconhece as dimensões estruturais da opressão, assentadas na tripla iniquidade, de classe, gênero e raça.

A qualificação como evento social foi incorporada aqui a partir de um ensaio de $\operatorname{Stark}^{14}$, para quem uma epidemia não deve ser vista como um intruso extraterritorial e biológico mas como um 'evento' com dimensões ideológicas e socioeconômicas, fruto de decisões políticas e econômicas (p. 681-682). A doença sempre foi um fato social, assim era para populações pré-industriais em seu convívio organizacional com o meio, mas tornou-se um produto quando a natureza passou a ser um obstáculo ao desenvolvimento capitalista. Epidemias são tanto socialmente determinadas quanto determinam desajustes sociais, e seu enfrentamento oportuniza ao Estado a realização de medidas repressivas que em outro cenário não seriam aceitáveis. Tanto vítimas quanto perpetradores definem historicamente contexto e significado da doença. A medicina clínica e a ideologia médica, aponta Stark, não negam a etiologia social da doença, mas reconhecem que os meios de progresso capitalista causam doença ao mesmo tempo em que ocultam a natureza histórica contingencial do processo, mostrando-o alternativamente, como um fato 'natural' (como 'progresso') e como resultado de uma escolha individual ou 'estilo de vida'14 (p. 701).

A dimensão social das pandemias é fato histórico. Biraben ${ }^{27}$ relata que os rituais da dança macabra diante da morte, cortejos de flagelados em peregrinação ou fuga, culpabilização dos pobres e mendigos, aumento de mortes entre idosos, aumento da violência e repercussões econômicas acompanharam a peste negra dos séculos XIV e XV. Segundo Biraben, desde o século XV, os ricos aprenderam a proteger-se relativamente bem, fugindo para suas propriedades no campo e isolando-se, o que não podiam fazer os pobres ${ }^{27}$ (p. 596).

Em maio de 2020, quando contabilizavam-se no mundo 270.000 mortes e 4,3 milhões de casos de COVID-19, Abrams e Szefler ${ }^{28}$ evidenciavam a grave desigualdade social implicada no processo e anteviam o que a história da pandemia mostra. Pobreza, falta de moradia ou situação de rua, raça ou etnicidade são determinantes de saúde relacionados pelos autores com a capacidade de cumprimento das medidas de isolamento social e restrição do contato físico e com o acesso aos serviços e recursos de saúde (p. 661). Medidas de distanciamento físico são difíceis de cumprir por quem vive em espaços precários. Tais condições afetam em maior escala a população negra que mais sofre com a desigualdade social. Abrams e Sezfler ressaltam que talvez os efeitos dos determinantes sociais em relação à COVID-19 sejam depreciados, e deveriam ser priorizados no enfrentamento desta e de pandemias futuras.

Convém, então, assinalar a referência crítica de Horton ${ }^{29}$ a uma perspectiva de determinação social, ao dizer que a COVID-19 não é uma pandemia, mas uma sindemia. O conceito, criado na antropologia médica por Singer ${ }^{30}$ referindo-se à aids, compreende a complexa interação entre doenças transmissíveis, doenças não transmissíveis e vulnerabilidade social, e é utilizado por Horton para assinalar a articulação do amplo espectro de manifestações clínicas e sociais da pandemia de COVID-19. 


\section{Críticas ao conceito de transição epidemiológica}

A ideia de transição epidemiológica se projeta na epidemiologia hegemônica a partir de um artigo do médico egípcio com atuação acadêmica norteamericana Abdel Omran ${ }^{31}$. Observamos que o autor tem, segundo Weisz e Olszynko$\mathrm{Gryn}^{32}$, vinculação com a política de controle da natalidade dos anos 1970. Omran ${ }^{31}$ acentua que a análise dos padrões de morte e adoecimento tem grande utilidade para conhecimento da dinâmica populacional e do controle da fertilidade, e sustenta que a teoria da transição epidemiológica enfoca os complexos padrões de mudança de saúde e doença e as interações com suas consequências demográficas, econômicas e sociológicas determinantes (p. 732). Afirmando embasar-se em amplas evidências que apontam para a substituição das pandemias de doenças infecciosas pelas doenças crônico-degenerativas e outras que atribui à ação humana, o autor propõe três modelos de transição epidemiológica que, como evidencia sua descrição, compõem um processo evolutivo cujo estágio mais avançado de desenvolvimento social corresponde à modernidade europeia: o modelo clássico ou ocidental, referido aos países ocidentais desenvolvidos; o acelerado, cujo exemplo é o Japão; o contemporâneo ou atrasado, referido a países da África, Ásia e América Latina, que se iniciou após a segunda guerra mundial (p. 732). A influência dos fatores médicos, diz Omran, não aparece antes do século XIX e a queda da mortalidade nos países ocidentais foi determinada primariamente por fatores ecobiológicos e socioeconômicos, ao passo que a transição no 'terceiro mundo' vem sendo significantemente influenciada pela tecnologia médica, cujas importação e utilização em programas de saúde pública têm tremendo impacto positivo no declínio mais recente da mortalidade ${ }^{31}$ (p. 741).

Considerando que nem sempre a epidemiologia clássica, com seu poderoso arsenal metodológico e técnico, atende à requisição de novos olhares para análise da realidade de países subdesenvolvidos, Barreto et al. ${ }^{18}$ questionam a ideia de transição epidemiológica, enquanto modelo macroteórico que pretende dar conta da globalidade das tendências históricas de morbi-mortalidade (p. 127-128). Os autores reconhecem o declínio geral da morbi-mortalidade, mas postulam que há diferenças nas mudanças dos indicadores epidemiológicos entre países desenvolvidos e subdesenvolvidos, relativas à comparação de doenças infecciosas e parasitárias com doenças crônico-degenerativas. Barreto et al. ${ }^{18}$ assinalam que a ideia de transição epidemiológica apresentada no artigo de Omran ${ }^{31}$ é inserida num enfoque neo-evolucionário da modernização, no qual sociedades 'tradicionais' transformam-se em sociedades 'adiantadas' ou 'modernas' mediante uma sequência determinada de etapas específicas, substituindo-se gradualmente o modo de viver tradicional/primitivo por um modo de viver moderno/ dinâmico (p. 134). A modernização é mostrada como transformação total da sociedade tradicional (pré-moderna) nos tipos de tecnologia, urbanização e organização social que caracterizam as nações adiantadas e economicamente prósperas (p. 134). Os autores afirmam a influência da teorização funcionalista de desenvolvimento social de Parsons na adoção de uma visão simples, evolucionista e etnocêntrica da mudança, ancorada na ideia de um padrão de desenvolvimento linear e unidirecional, calcada naquilo que parece ter acontecido em países da Europa Ocidental e nos Estados Unidos (p. 135). O pressuposto é insustentável porque universaliza um ponto de vista sobre sequencias históricas, subestimando a complexidade estrutural dos fatores sociais (p. 135). Perspectivas como a de Omran, segundo Barreto et al., tratam os países subdesenvolvidos partindo de uma visão idealizada do desenvolvimento europeu, fundamentada em proposições altamente generalizadas e deterministas, que não considera adequadamente a variabilidade e flexibilidade dos sistemas sociais e as reações protagonizadas pela população diante das mudanças ${ }^{18}$ (p. 136).

Menénde ${ }^{19}$ revela o caráter a-histórico que envolve o uso de conceitos trazidos das ciências sociais para a epidemiologia. Ao comparar os conhecimentos antropológico e epidemiológico o autor situa a teoria da transição epidemiológica como proposta evolucionista e desenvolvimentista de sociedade relacionada a um elogio ideológico da modernidade.

$\mathrm{O}$ resgate das análises de Barreto et al. ${ }^{18}$ e de Menendez ${ }^{19}$ é importante para demarcar a originalidade do ponto de vista decolonial, desde que não é esta a perspectiva teórica assumida pelos autores quando questionam a ordenação científica da Saúde Coletiva. Pensamos que o posicionamento decolonial dá transcendência histórica à crítica epistemológica.

Acompanhamos Mignolo $^{10}$ tanto no apontamento de que a reflexão decolonial deve ser entendida como opção particular de interpretação, como também no que se relaciona ao forte impacto do poder revelador da teorização, ao permitir perceber a colonialidade como o lado 
constitutivo e mais escuro da ideia de modernidade eurocêntrica (p. 2). Interpretamos, neste ensaio, o giro decolonial, ético-político e teórico, de que fala Maldonado-Torres ${ }^{11}$, como releitura crítica capaz de produzir ressignificações históricas e novas versões epistemológicas para a epidemiologia.

\section{Uma leitura decolonial da contemporaneidade da pandemia}

O pensamento decolonial, segundo Ballestrin $^{33}$, surge no final dos anos 1990 quando intelectuais latino-americanos realizam um movimento de crítica epistemológica radical com a criação do Grupo Modernidade/Colonialidade, renovando as ciências sociais. Produzem uma genealogia da argumentação pós-colonial e transcendem outros estudos sobre a subalternidade. A intenção é ultrapassar a reflexão pós-colonial, cujo foco principal é o imperialismo britânico, e outras teorizações descoloniais.

O uso do termo decolonial expressa insurgência em relação às propostas descoloniais que, embora contrapostas à dominação colonialista, diferem do movimento latino-americano ${ }^{33}$. O decolonial confronta radicalmente a universalização da modernidade eurocêntrica que forja a ciência hegemônica, procurando desvelar as diversas formas de opressão e racismo matricialmente incorporadas à colonialidade do poder, do saber, do ser, em sua relação com a América Latina.

Quijano $^{12}$ é autor pioneiro na perspectiva decolonial, tendo introduzido a ideia de colonialidade do poder que inspirou as de colonialidade do saber e do ser. Para o autor, a invenção da ideia de raça fundamenta a dominação eurocêntrica sobre as populações latino-americanas. Raça é construção mental funcional que demarca hierarquias de poder entre colonizadores e colonizados, dissimulando-se como suposta distinção estrutural biológica. A partir da ideia de raça foram produzidas formas de relações e identidades sociais como índios, negros, mestiços e brancos, constitutivas da dominação colonizadora europeia. Criou-se, assim, no sistema-mundo capitalista um novo padrão universalizado de poder no qual se ancora o controle das relações de trabalho, recursos e produtos. Sobre esta matriz foi também constituída a hierarquia do conhecimento, sendo incorporadas a intelectualidade e a cultura ao processo de dominação. Populações colonizadas foram expropriadas de suas expressões simbólicas, religiosidade, subjetividade, co- nhecimento, por meio da geração de uma nova perspectiva temporal de história evolucionista traçada desde um estado de natureza ao de civilização, onde diferenças de identidade racial e gênero, bem como aquelas entre subdesenvolvimento e desenvolvimento, respectivamente, são encarnadas na América Latina e resto do mundo e na Europa (p. 121). A colonialidade do poder, para Quijano, é estruturada sobre uma trajetória civilizatória contínua unilinear racista, um novo espaço-tempo que inferioriza os não-europeus e culmina na modernidade europeia, assumida como dimensão material e subjetiva universal de mudança e futuro $^{12}$ (p. 125, 127).

Para Mignolo ${ }^{10}$ a globalização tem dois lados: o da narrativa da modernidade e o da lógica da colonialidade (p. 3). Mignolo pensa a colonialidade, conceito que buscou em Quijano, como o lado escuro da modernidade. O discurso da modernidade define o nascimento da civilização a partir da dominação europeia, celebrando as conquistas inscritas nesta perspectiva histórica e ocultando a colonialidade. Espaço e tempo foram colonizados, em sentido econômico e epistemológico, para sustentação do projeto. A ciência hegemônica estruturou-se sob a soberania europeia, como conhecimento capaz de dominar a natureza. O convívio respeitoso com a natureza, fundamento de civilizações seculares, tornou-se, diante da ciência hegemônica eurocêntrica, uma miscelânea de narrativas alternativas que não devem ser tratadas como conhecimento. Hierarquias raciais, de gênero, espiritual/religiosa, estética, epistêmica, linguística, conformadas a uma concepção de sujeito moderno padronizada segundo a civilização europeia, branca, patriarcal, cristã, tornaram-se modelo para a humanidade ${ }^{10}$ (p. 11).

$O$ engendramento de um tempo histórico universal linear com início na modernidade europeia, revelado pela crítica decolonial, é elemento estrutural da formulação clássica da ideia de transição epidemiológica e sua postulação de controle sobre as doenças infecciosas. Isto contextualiza o caráter surpreendente da pandemia de COVID-19, diante da qual somam-se perplexidade e despreparo científico e político.

A Pachamama, mãe terra das cosmologias indígenas latino-americanas, como esclarece Mignolo $^{10}$, não compreende a distinção entre natureza e cultura que marca a civilização ocidental. A natureza foi colonizada e expropriada pelo discurso teológico cristão, separada da cultura e tornou-se fonte de recursos objetivada para a exploração capitalista. A teorização decolonial amplia e ressignifica a crítica à teoria da transição 
epidemiológica quando esta sustenta a pretensão humana de reinar sobre a natureza, expressa na certeza de eliminar as doenças infectocontagiosas atribuindo à biomedicina ocidental tal capacidade. A ideia de que as epidemias de doenças infecciosas transmissíveis pertencem ao passado evidencia, à luz decolonial, a colonização do saber epidemiológico.

A ênfase nas ações de ordem biomédica exclui do enfrentamento da pandemia o trabalho dos governos com organizações populares e movimentos sociais, que, reconhecidamente, têm mais presença comunitária, identificação e familiaridade com realidades locais. O desmonte das políticas públicas de assistência e concessão de benefícios sociais e a renegação dos movimentos sociais marcam as políticas neoliberais, fragilizando a estrutura e a capacidade dos serviços públicos de saúde para responder à pandemia, tanto mais onde recursos econômicos são escassos e a população mais vulnerável.

Santos $^{8,9}$, autor influente nas epistemologias críticas da complexidade e na discussão decolonial, com seu reconhecimento das Epistemologias do Sul, contrapõe à invisibilização e ao epistemicídio dos saberes populares a construção do conhecimento juntamente com os movimentos sociais. Reportando-se à pandemia de COVID-19, afirma que devemos aprender com agentes sociais tão diversos como artistas e povos indígenas a considerar as experiências acumuladas que podem se mostrar uma forma efetiva de mirar o futuro ${ }^{34}$ (p. 37).

Poucas experiências humanas evidenciaram tanto o poder político de decidir soberanamente sobre a vida e a morte como a pandemia de COVID-19, um reino do imaginário profícuo para realização da exceção, como apontou $\operatorname{Stark}^{14}$ ao tratar epidemias como eventos sociais. A iniquidade social se pronuncia quando, em nome do controle da epidemia, ações governamentais de saúde e apoio econômico constituem exercício de poder conformado à violência institucionalizada sobre os corpos executada pelo Estado. Sob alegação de atendimento emergencial e proteção da vida, ações constituem-se como forma de exclusão e racismo ao dividir pessoas em grupos de risco que mais ou menos têm chance ou direito de viver e morrer. Defende-se a emergência contingencial da razão econômica e jamais privilegia-se a mudança social estrutural, e assim realiza-se a necropolítica de que fala $\mathrm{Mbembe}^{35}$, inspirando-se no biopoder de Foucault. Seja pela corrupção, pela mentira, pela desorganização, pelo erro, pela arrogância, pelo preconceito, pela intenção política discriminatória, tanto ou mais do que pela ação disciplinadora do vírus, serão os vulneráveis, os pobres, os negros, os índios, os velhos, os que, definidos como de maior risco pelo saber epidemiológico, mais encontrarão a morte. As classificações epidemiológicas de risco podem servir à aceitação tácita deste destino trágico.

Privilegiando a quantificação, a epidemiologia opera suas classificações de risco categorizando objetivamente grupos populacionais na composição de variáveis estatísticas. Distinções de renda, atividades ocupacionais, sexo e cor de pele são operadas de forma binarizada, obscurecendo e mesmo invisibilizando para o raciocínio epidemiológico considerações críticas sobre classe social, gênero, racialização.

Relacionados à COVID-19, um estudo de base populacional que procura enfatizar a questão da raça aponta a dificuldade da referência à cor da pele para expressar contexto e posição social $^{36}$ (p. 9) e uma revisão sobre a necropolítica sugere incipiência na caracterização da identidade étnica nas análises epidemiológicas da pan$\operatorname{demia}^{37}$ (p. 4211). O questionamento decolonial sobre os binarismos pode dar novo sentido ao apontamento dos autores citados.

Os binarismos têm a ver com a fixação de extremos opostos nas relações de classe, gênero, raça e outras, de modo a fortalecer hierarquizações espúrias e não alcançar nuances, hibridizações identitárias, traduções culturais próprias de sociedades marcadas por multiplicidades e contradições $^{38}$. Ao evocarem exclusão mútua, binarismos impossibilitam o deslizamento de sentidos que contextualiza os processos sociais.

A feminista decolonial Lugones ${ }^{39}$ se refere aos binarismos afirmando que a cultura da modernidade ocidental organiza o mundo a partir de categorias ontológicas atomizadas e separáveis, bloqueando interseções entre classe, raça, sexualidade, gênero. A dicotomização central da modernidade colonial vem da consideração do é humano e não humano, e confere estatuto de ideal de humanidade e perfeição para homens, heterossexuais, brancos, cristãos, europeus.

As variáveis epidemiológicas, em sua objetividade, definem fronteiras de exclusão, e assim pode também ser pensada a oposição entre saúde e doença, que, no entender de Almeida Filho $^{40}$, representa uma fragilidade fundamental na episteme epidemiológica. Para o autor, como subsidiária da clínica, a teoria epidemiológica tem dificuldade em lidar com a categoria saúde, restando-lhe o tratamento parcial e residual da doença coletiva pelo risco e seus fatores (p. 7). 
Pensamos que, ao alimentar distinção fechada, o binarismo saúde/doença reforça o peso colonizador da biomedicina ocidental sobre o conhecimento epidemiológico, fragilizando o reconhecimento da complexidade social e política que orienta as epidemias.

Os aportes da reflexão decolonial podem, com sua radicalidade, fortalecer a análise crítica do saber epidemiológico. Ao apontamento decolonial o questionamento epistemológico da Saúde Coletiva toma um sentido original revelador da opressão colonizadora que estrutura o pensamento epidemiológico e, frequentemente, não se revela ao espelho.

\section{Considerações finais: incertezas, bifurcações, inédito-viável}

Para Santos ${ }^{34}$, o coronavírus é nosso contemporâneo ao compartir conosco as contradições de nosso tempo, o passado que não é passado e o futuro que virá ou não (p. 35). A cruel pedagogia do vírus nos ensina das consequências da agressão à natureza. Não sabemos se o que virá será para o bem ou para o mal e à narrativa do medo deverá se contrapor a da esperança (p. 40).

Prigogine $^{41}$ observou bifurcações que inserem a perspectiva histórica em sistemas químicos levando-os ao não determinismo, rompendo linearidade e ordem de equilíbrio anterior (p. 23). Pequenas flutuações em sistemas abertos criam estruturas instáveis duradouras distantes do equilíbrio e pouco previsíveis. Irreversibilidade do tempo, assimetria, mudança compõem a reflexão humanizadora de Prigogine sobre a complexidade, e ao entender o tempo como criação ele sugere associar as bifurcações, e as transformações que trazem, tanto aos sistemas naturais como sociais $^{42}$ (p. 74).

As bifurcações prigogineanas e seu potencial de transformação social são referidos por Santos em sua crítica decolonial, caracterizando a crise epistemológica e política que vivemos ${ }^{43}$ (p. 432) ou apontando a possibilidade de mudanças socialmente emancipadoras $^{44}$ (p. 289). Sevalho ${ }^{45}$ associa, em uma epistemologia que vê o tempo como criação, a complexidade de Prigogine e o pensamento de Paulo Freire, ilustrando a relação com o conceito freireano de inédito viável na perspectiva da esperança.

Em Freire ${ }^{46}$, inédito viável remete à superação de situações-limites e não-determinismo (p. 110). O conceito diz da conscientização da possibilidade de emancipação e se contrapõe à opressão social e à conformidade com a ideia de que a justiça social é inalcançável. Bifurcações e inédito viável miram a mudança, o novo.

A desobediência associada com a epidemia, segundo Stark ${ }^{14}$, pode crescer de acordo com as medidas executadas pelas autoridades para racionalizar o sofrimento (p. 690). Movimentos populares surgidos no contexto de epidemias podem transcender o enfrentamento da doença, e, então, atentemos para as lutas antirracistas nascidas durante a pandemia de COVID-19, que tomaram o mundo.

É difícil lidar com a longa duração do tempo e ao viver o drama desejamos soluções favoráveis no tempo curto. Reações contra a privação da liberdade e perdas sociais devem surgir, mas podem não se dar de modo a constituir a conscientização crítica sobre a iniquidade social. O futuro pós-pandemia pode configurar o enrijecimento perverso do neoliberalismo ou nos levar a sociedades mais justas.

Discursos solidários constroem mundos em contraposição à desinformação politicamente orientada. Devemos nos empenhar na construção de uma ciência crítica e socialmente emancipadora com a convicção de que um outro mundo é possível. 


\section{Referências}

1. Santos M. Técnica, espaço, tempo. São Paulo: HUCITEC; 1994.

2. Jordan D, Tumpey T, Jester B. The deadliest flu: the complete story of the Discovery and reconstruction of the 1918 pandemic virus. 2019 [cited 2020 Jun 22] Available from: https://www.cdc.gov/flu/pandemic -resources/reconstruction-1918-virus.html

3. Ujvari SC. Meio ambiente e epidemias. São Paulo: Senac; 2004.

4. Pinto PAP. China e Sudeste Asiático: diferenças e semelhanças de percepção quanto a questões atuais. Revista Brasileira de Política Internacional 1997; 40(2):144-165.

5. Sevalho G. Velocidade/aceleração temporal e infecções emergentes: epidemiologia e tempo social. Hist Cienc Saude Manguinhos 1996; III(2):217-236.

6. Prigogine I, Stengers I. A nova aliança. Brasília: Universidade de Brasília; 1984.

7. Morin E. Introdução ao pensamento complexo. Porto Alegre: Sulina; 2007.

8. Santos BS. Um discurso sobre as ciências. Porto: Afrontamento; 2008.

9. Santos BS. O fim do império cognitivo - a afirmação das epistemologias do Sul. Belo Horizonte: Autêntica; 2019.

10. Mignolo W. Colonialidade - o lado mais escuro da modernidade. Revista Brasileira de Ciências Sociais 2017; 32(94):1-17.

11. Maldonado-Torres N. La descolonización e el giro des-colonial. Tabula Rasa 2008; 9:61-72.

12. Quijano A. Colonialidade do poder, eurocentrismo e America Latina. In: Lander E, organizadores. A colonialidade do saber: eurocentrismo e ciências sociais. Perspectivas latino-americanas. Buenos Aires: CLACSO; 2005. p. 116-42 [cited 2020 Jul 5] Available from: https://edisciplinas.usp.br/pluginfile.php/2591382/ mod_resource/content/1/colonialidade_do_saber_ eurocentrismo_ciencias_sociais.pdf

13. Adorno TW. O ensaio como forma. In: Adorno TW. Notas de literatura I. São Paulo: Editora 34; 2003. p. 15-46.

14. Stark E. The epidemic as a social event. Int $J$ Health Serv 1977; 7(4):681-705.

15. Castiel LD. O buraco e o avestruz - a singularidade do adoecer humano. Campinas: Papirus; 1994.

16. Almeida Filho N. A clínica e a epidemiologia. Salvador: APCE-Abrasco; 1997.

17. Ayres JRM. Sobre o risco - para compreender a epidemiologia. São Paulo: Hucitec; 1997.

18. Barreto ML, Carmo EH, Noronha CV, Neves RBB, Alves PC. Mudanças dos padrões de morbi-mortalidade: uma revisão crítica das abordagens epidemiológicas. Physis 1993; 3(1):127-146.

19. Menéndez EL. Antropologia médica e epidemiologia. Processo de convergência ou processo de medicalização? In: Alves PC, Rabelo MC, organizadores. Antropologia da saúde - traçando identidade e explorando fronteiras. Rio de Janeiro: Fiocruz/Relume Dumará; 1998: p. 71-93.

20. Johns Hopkins University Medicine - Coronavirus Resource Center. [cited 2021 Jun 7] Available from: https://coronavirus.jhu.edu/map.html
21. Nora P. O acontecimento e o historiador do presente. In: Le Goff J, Ladurie ELR, Duby G e outros. A Nova História. Lisboa: Edições 70; 1989. p. 45-55.

22. Braudel F. A história frente ao presente. In: Braudel, F. História e ciências sociais. Lisboa: Editorial Presença: 1986. p. 123-33.

23. Agamben G. O que é o contemporâneo? In: Agamben G. O que é o contemporâneo e outros ensaios. Chapecó: Unochapecó; 2009. p. 55-73.

24. Kuhn T. A estrutura das revoluções científicas. São Paulo: Perspectiva; 1989. p. 592-597.

25. Dahlgren G, Whitehead M. Policies and Strategies to promote social equity in health. Stockholm: Institute for Future Studies; 1991.

26. Breilh J. Epidemiologia crítica - ciência emancipadora e interculturalidade. Rio de Janeiro: Fiocruz; 2006.

27. Biraben J-N. Peste. In: Burguière A, organizadores. Dicionário das Ciências Históricas. Rio de Janeiro: Imago; 1993. p. 592-97.

28. Abrams EM, Szefler SJ. COVID-19 and the impact of social determinants of health. The Lancet 2020; 8:661663.

29. Horton R. Offline: COVID-19 is not a pandemic. The Lancet 2020; 396:874.

30. Singer M. Aids and the health crisis of the U. S. urban poor; the perspective of critical medical antrophology. Soc Sci Med 1994; 39(7):931-948.

31. Omran A. The epidemiologic transition. A theory of the epidemiology of population change. Milbank Q. 1971; 49(4): 509-538.

32. Weisz G, Olszynko-Gryn J. The theory of epidemiologic transition: the origins of a citation classic. J Hist Med 2010; 65:287-326.

33. Ballestrin L. América Latina e o giro decolonial. Revista Brasileira de Ciências Políticas 2013; 11:89-117.

34. Santos BS. El coronavírus y nuestra contemporaneidade. In: Bringel, B, Pleyers, G, organizadores. Alerta global-Politicas, movimentos sociales y futuros en disputa en tempos de pandemia. Buenos Aires: Clacso; 2020. p. 35-40 [cited 2020 Aug 10] Available from: http:// biblioteca.clacso.edu.ar/clacso/se/20200826014541/ Alerta-global.pdf

35. Mbembe A. Necropolítica. Arte \& Ensaios. Revista do PPGAV/EBA/UFRJ 2016; 32:123-151.

36. Ribeiro KB, Ribeiro AF, Veras MASM, Castro MC. Social inequalities and COVID-19 mortality in the city of São Paulo, Brazil. Int J Epidemiol 2021; 00(00):111. [cited 2021 Jun 7]. Available from: https://www. ncbi.nlm.nih.gov/pmc/articles/PMC7989375/pdf/ dyab022.pdf

37. Santos HLPC, Maciel FBM, Santos KR, Conceição CDVS, Oliveira RS, Silva NRS, Prado NMBL. Necropolítica e reflexões acerca da população negra no contexto da pandemia de COVID-19 no Brasil: uma revisão bibliográfica. Cien Saude Colet 2020; 4211-4224.

38. Hall S. Diásporas, ou a lógica da tradução cultural. Matrizes 2016; 10(3):47-58.

39. Lugones, M. Rumo a um feminismo descolonial. Estudos Feministas 2014; 22(3):935-952.

40. Almeida Filho N. O conceito de saúde: ponto-cego da Epidemiologia? Rev Brasil Epidemiol 2000; 3(1-3):420. 
41. Prigogine I. As leis do caos. São Paulo: Unesp; 2002.

42. Prigogine I. O fim das certezas. São Paulo: Unesp; 1996.

43. Santos BS. Os processos da globalização. In: Santos BS. Construindo as Epistemologias do Sul: Antologia essencial. Volume I: Para um pensamento alternativo de alternativas . In: Meneses MP, Nunes JA, AñonCL, Bonet AA, Gomes NL, organizadores. Buenos Aires: Clacso; 2018. p. 397-483. [acessado 2020 jun 02] Disponível em: http://biblioteca.clacso.edu.ar/clacso/ se/20181203044534/Antologia_Boaventura_PT2.pdf.

44. Santos BS. Tradução intercultural: diferir e partilhar com Passionalitá. In: Santos BS. Construindo as Epistemologias do Sul: Antologia essencial. Volume I: Para um pensamento alternativo de alternativas. In: Meneses MP, Nunes JA, Añon CL, Bonet AA, Gomes, NL, organizadores. Buenos Aires: Clacso; 2018. p. 261-95 [acessado 2020 ago 8]. Disponível em: http://biblioteca.clacso.edu.ar/clacso/se/20181203044534/Antologia_Boaventura_PT2.pdf

45. Sevalho G. Ensaio sobre a ideia de tempo em Paulo Freire: a presença da duração bergsoniana. Pro-Posições 2018; 29(1):172-191.

46. Freire P. Pedagogia do oprimido. Rio de Janeiro: Paz e Terra; 1978.

Artigo apresentado em 16/10/2020

Aprovado em 10/08/2021

Versão final apresentada em 12/08/2021

Editores-chefes: Romeu Gomes, Antônio Augusto Moura da Silva 